\title{
Biofilm formation, antimicrobial susceptibility and virulence genes of Uropathogenic Escherichia coli isolated from clinical isolates in Uganda
}

Paul Katongole ${ }^{1,2^{*}}$ D, Fatuma Nalubega ${ }^{1}$, Najjuka Christine Florence ${ }^{1}$, Benon Asiimwe ${ }^{1}$ and Irene Andia ${ }^{3}$

\begin{abstract}
Introduction: Uropathogenic E. coli is the leading cause of Urinary tract infections (UTIs), contributing to 80-90\% of all community-acquired and 30-50\% of all hospital-acquired UTIs. Biofilm forming Uropathogenic E. coli are associated with persistent and chronic inflammation leading to complicated and or recurrent UTIs. Biofilms provide an environment for poor antibiotic penetration and horizontal transfer of virulence genes which favors the development of Multidrug-resistant organisms (MDRO). Understanding biofilm formation and antimicrobial resistance determinants of Uropathogenic E. coli strains will provide insight into the development of treatment options for biofilm-associated UTIs. The aim of this study was to determine the biofilm forming capability, presence of virulence genes and antimicrobial susceptibility pattern of Uropathogenic E. coli isolates in Uganda.
\end{abstract}

Methods: This was a cross-sectional study carried in the Clinical Microbiology and Molecular biology laboratories at the Department of Medical Microbiology, Makerere University College of Health Sciences. We randomly selected 200 Uropathogenic E. coli clinical isolates among the stored isolates collected between January 2018 and December 2018 that had significant bacteriuria (> 10 CFU). All isolates were subjected to biofilm detection using the Congo Red Agar method and Antimicrobial susceptibility testing was performed using the Kirby disk diffusion method. The isolates were later subjected PCR for the detection of Urovirulence genes namely; Pap, Fim, Sfa, Afa, Hly and Cnf, using commercially designed primers.

Results: In this study, 62.5\% (125/200) were positive biofilm formers and 78\% (156/200) of these were multi-drug resistant (MDR). The isolates were most resistant to Trimethoprim sulphamethoxazole and Amoxicillin (93\%) followed by gentamycin (87\%) and the least was imipenem (0.5\%). Fim was the most prevalent Urovirulence gene (53.5\%) followed by Pap (21\%), Sfa (13\%), Afa (8\%), Cnf (5.5\%) and Hyl (0\%).

Conclusions: We demonstrate a high prevalence of biofilm-forming Uropathogenic E. coli strains that are highly associated with the MDR phenotype. We recommend routine surveillance of antimicrobial resistance and biofilm formation to understand the antibiotics suitable in the management of biofilm-associated UTIs.

Keywords: Biofilms, Uropathogenic E. coli, Virulence genes, Antimicrobial resistance

\footnotetext{
* Correspondence: paul.katongole@gmail.com

'Department of Medical Microbiology, College of Health Sciences Makerere University, Kampala, Uganda

${ }^{2}$ Department of Medical Biochemistry, College of Health Sciences Makerere University, Kampala, Uganda

Full list of author information is available at the end of the article
}

(c) The Author(s). 2020 Open Access This article is licensed under a Creative Commons Attribution 4.0 International License, which permits use, sharing, adaptation, distribution and reproduction in any medium or format, as long as you give appropriate credit to the original author(s) and the source, provide a link to the Creative Commons licence, and indicate if changes were made. The images or other third party material in this article are included in the article's Creative Commons licence, unless indicated otherwise in a credit line to the material. If material is not included in the article's Creative Commons licence and your intended use is not permitted by statutory regulation or exceeds the permitted use, you will need to obtain permission directly from the copyright holder. To view a copy of this licence, visit http://creativecommons.org/licenses/by/4.0/ The Creative Commons Public Domain Dedication waiver (http://creativecommons.org/publicdomain/zero/1.0/) applies to the data made available in this article, unless otherwise stated in a credit line to the data. 


\section{Background}

Urinary tract infections (UTIs) are one of the leading causes of morbidity affecting 150 million people each year worldwide [1]. E.coli is the most predominant pathogen causing over $80-90 \%$ of community-acquired and $30-50 \%$ of hospital-acquired UTIs [2]. The ability of Uropathogenic E.coli (UPEC) to invade, grow, ascend and persist in the uroepithelium is dependent on the ability to form biofilms and utilize different virulence factors [3]. These factors however are also countered by the hosts defenses such as urinary flow, expression of cytokines e.g. IL-8, Uro-epithelial defensin peptides such as Tamm-Horsfall protein (THP) and low molecular weight oligosaccharides. Hence the pathogenesis of UTIs relies on the balance between bacterial and host factors [4]. Biofilms represent an assemblage of microbial cells that is irreversibly associated with a surface and enclosed in a matrix of primarily polysaccharide material [5]. Biofilms provide a survival strategy to the bacteria by positioning them to effectively use the available nutrients and prevent access to antimicrobial agents, antibodies and white blood cells [6]. They have also been found to harbor a large number of antibiotic inactivating enzymes such as beta-lactamases hence creating an island of antimicrobial resistance [7].

UPEC strains encode a number of virulence genes that are associated with severe or recurrent UTIs, among these include; P fimbriae (pap), type1-fimbriae (fim-H), afimbrial-adhesin1 (afa1), S-fimbriae (sfa), hemolysin (hly), cytotoxic-necrotizing-factor (cnf1), aerobactin among others [8]. These help the organism to colonize the host surfaces, avoid and or subvert host defense mechanisms, injure and or invade host cells and tissues and incite a noxious inflammatory response hence leading to clinical disease [9]. Biofilm forming bacteria produce matrix composed of proteins, extracellular DNA and polysaccharides, these provide several benefits to the bacterial communities including; protection against immune cells, adhesion (facilitated by bacterial adhesins) and structure [10].

Several studies have demonstrated antimicrobial resistance among UPEC with increasing trends to the most commonly used antibiotics such as ciprofloxacin, trimethoprim-sulphamethoxazole among others [11, 12]. These antimicrobial resistance patterns tend to differ from one geographical region to another [13]. Timely and appropriate treatment is crucial in the management of UTIs; however, this should be based on evidence from regional antimicrobial susceptibility results, knowledge of the virulence genes and biofilm formation [14, 15]. Understanding the link between biofilm formation, presence of virulence genes and antimicrobial resistance distribution in UPEC strains is key in designing effective strategies and measures for prevention and management of UTIs especially severe, recurrent and complicated UTIs [14]. In this study, our goal was to determine the biofilm forming capability, presence of virulence genes and antimicrobial susceptibility pattern of UPEC clinical isolates in Uganda.

\section{Methods}

Bacterial strains and detection of Uropathogenic $E$. coli virulence genes

This was a cross-sectional study carried out from January 2019 to April 2019 at the Department of Medical Microbiology, Makerere University College of health sciences. A total of $200 \mathrm{E}$. coli isolates (collected and stored January to December 2018) that had been recovered from urine samples of patients with UTIs at Mulago National referral hospital outpatient. The isolates were from pure culture, identified and confirmed biochemically using standard laboratory SOPs. The DNA extraction was carried out using boiling lysis method as described by Reischl et al 2000 [16].

We used commercially designed primers for Pap, Fim, $S f a, A f a, H l y$, and Cnf genes adapted from a study by Ruike Zhao et al 2015 [17]. The conditions and oligonucleotide sequences are as shown in Table 1 . The amplified PCR products were visualized by $1.5 \%$ ethidium bromide staining after gel electrophoresis. The amplification of virulence genes was carried out in a Thermal Cycler (Eppendorf Master Cycler) under the following PCR conditions; denaturation at $94{ }^{\circ} \mathrm{C}$ for $2 \mathrm{~min}$, followed by 30 cycles of denaturation at $94{ }^{\circ} \mathrm{C}$ for $60 \mathrm{~s}$, annealing at $63^{\circ} \mathrm{C}$ for $30 \mathrm{~s}$, and extension at $72{ }^{\circ} \mathrm{C}$ for 90 $\mathrm{s}$, with a final extension at $72^{\circ} \mathrm{C}$ for $5 \mathrm{~min}$. Strain $\mathrm{J96}$ was used as positive control for Pap, Fim, Sfa, Hly, and Cnf sequences and strain K10 was used as positive control for Afa. Distilled water is used as negative control.

Table 1 Oligonucleotide primers used for amplification of virulence genes among UPEC isolates

\begin{tabular}{llll}
\hline Primer name & Oligonucleotide sequence (5'-3') & Sizes (bp) & Gene \\
\hline PapC-F & GACGGCACTGCTGCAGGGTGGGG & 328 & papC \\
Pap-C-R & ATATCCTITCTGCAGGGATGCAATA & & \\
Fim-H-F & TGTACTGCTGATGGGCTGGTC & 564 & fimH \\
Fim-H-R & GGGTAGTCCGGCAGAGTAACG & & \\
Sfa-F & CTCCGGAGAACTGGGTGCATCTTAC & 410 & Sfa \\
Sfa- $R$ & CGGAGGAGTAATTACAAACCTGGCA & & \\
Afa-F & GCTGGGCAGCAAACTGATAACTCTC & 750 & Afa \\
Afa- $R$ & CATCAAGCTGTTGTTCGTCCGCCG & & \\
HlyA-F & AACAAGGATAAGCACTGTTCTGGCT & 1177 & hlyA \\
HIyA-R & ACCATATAAGCGGTCATTCCCGTCA & & \\
Cnf1-F & AAGATGGAGTTCCTATGCAGGAG & 498 & cnf1 \\
Cnfl-R & TGGAGTTCCTATGCAGGAG & & \\
\hline
\end{tabular}

Primers and sequences adapted from Ruike Zhao et al 2015 


\section{Detection of biofilm formation and antimicrobial susceptibility testing}

For all E. coli isolates, biofilm formation was detected by Congo red agar method (CRA) as described by Freeman et al 1989 [18]. CRA medium was prepared by mixing brain heart infusion broth (Oxoid, UK) $37 \mathrm{~g} / \mathrm{L}$, sucrose $50 \mathrm{~g} / \mathrm{L}$, agar No. 1 (Oxoid, UK) $10 \mathrm{~g} / \mathrm{L}$ and Congo red indicator (Oxoid, UK) $8 \mathrm{~g} / \mathrm{L}$. The Congo red stain was prepared as a concentrated aqueous solution and autoclaved $\left(121^{\circ} \mathrm{C}\right.$ for $\left.15 \mathrm{~min}\right)$ separately from the other medium constituents [18]. Congo red stain was later added to the autoclaved brain heart infusion agar with sucrose at $55^{\circ} \mathrm{C}$. CRA plates were later inoculated with test organisms and incubated at $37{ }^{\circ} \mathrm{C}$ for $24 \mathrm{~h}$ aerobically. Black colonies with a dry crystalline consistency indicated biofilm production whereas no-biofilm formation was identified as red or pink crystalline colonies. E. coli ATCC 25922 was used as positive control and Staphylococcus aureus ATCC 25932 as negative control for the CRA method.

Antimicrobial Susceptibility testing was performed using Kirby Bauer Disk diffusion method on Mueller Hinton agar according to the Clinical Laboratory Standard Institute (CLSI) 2014. Antibiotics tested for included; ampicil-

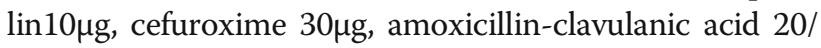
$10 \mu \mathrm{g}$, gentamycin $10 \mu \mathrm{g}$, trimethoprim-sulphamethoxazole $1.25 / 23.5 \mu \mathrm{g}$, chloramphenicol $5 \mu \mathrm{g}$, ciprofloxacin $5 \mu \mathrm{g}$, ceftriaxone $30 \mu \mathrm{g}$, ceftazidime $30 \mu \mathrm{g}$, meropenem $10 \mathrm{ug}$, nalidixic acid $30 \mu \mathrm{g}$, and nitrofurantoin $300 \mu \mathrm{g}$. E. coli ATCC 25922 was used as positive control for the antimicrobial susceptibility testing.

\section{Statistical analysis}

The data was cleaned, double-checked and exported to STATA version 14 for statistical analysis. The Chisquare test was used to evaluate the correlations

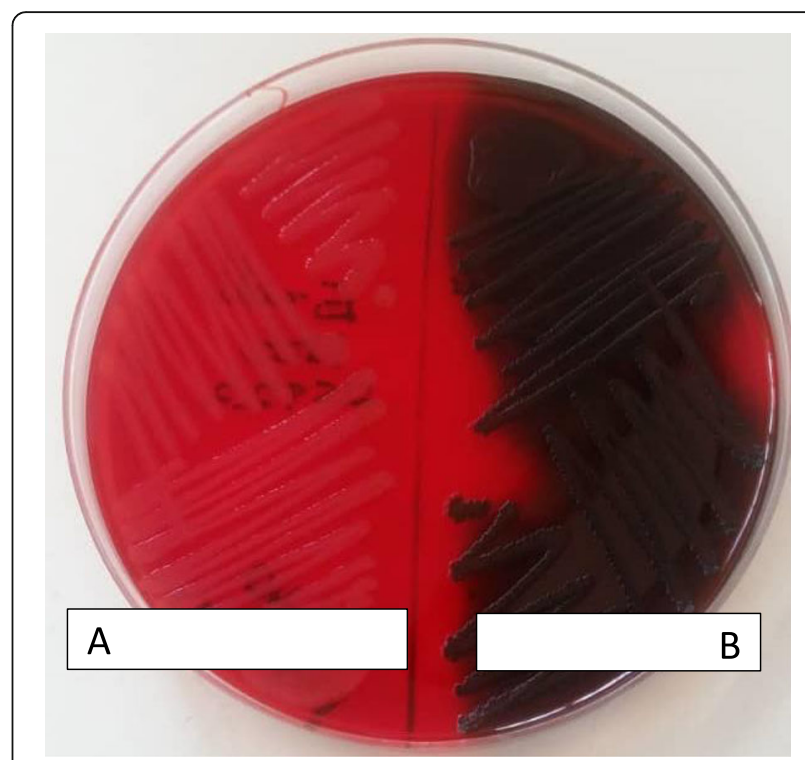

Fig. 1 Congo Red Agar plates showing biofilm and none-biofilm forming UPEC isolates

between variables. $P$ - values of correlations less than 0.05 were considered statistically significant.

\section{Ethical considerations}

The study obtained approval from the Research and Ethics committee of the School of Biomedical Sciences, College of Health Sciences Makerere University (SBSHDREC-515) and the Uganda National Council of Science and Technology.

\section{Results}

Out of 200 E. coli clinical isolates, 125 (62.5\%) were able to produce biofilm. All isolates that produced dark crystalline colonies on CRA were considered for positive

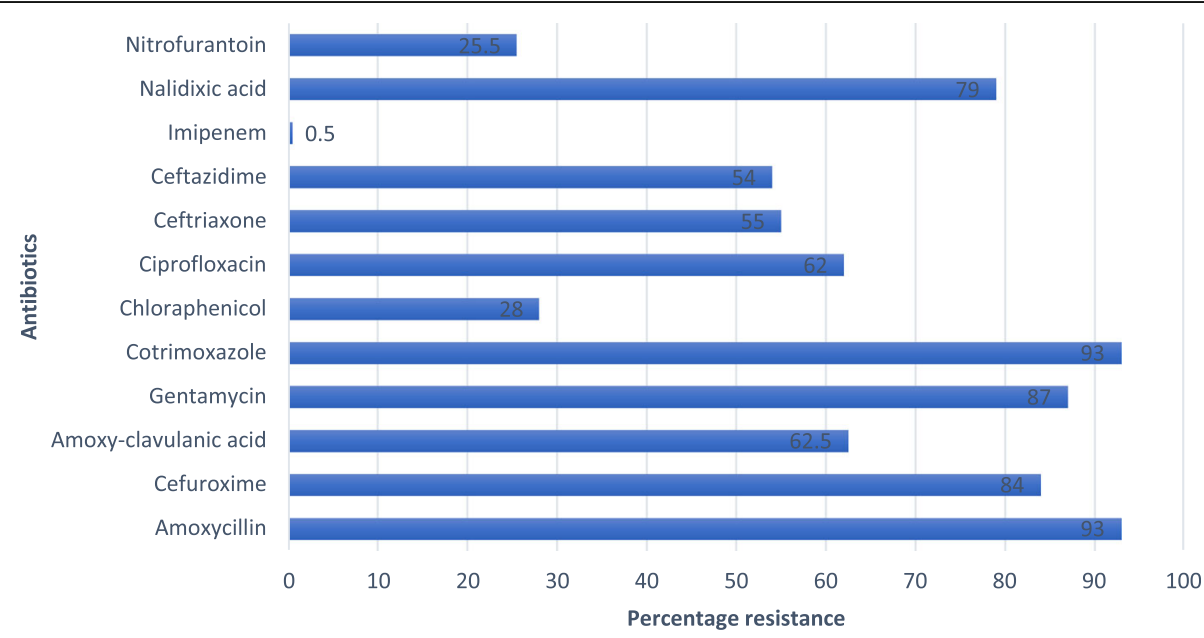

Fig. 2 Percentage resistance of Uropathogenic E.coli Isolates $(N=200)$ to different antibiotics 
Table 2 Multi-drug resistance among biofilm forming and nonbiofilm forming UPEC isolates

\begin{tabular}{ll}
\hline Biofilm status & MDR phenotype, $\mathrm{n}(\%)$ \\
\hline Biofilm formation & $100(64 \%)$ \\
No -Biofilm formation & $56(36 \%)$ \\
\hline
\end{tabular}

biofilm formation while those that produced red or pink colonies were considered no biofilm formation as shown in Fig. 1.

Among all the E. coli isolates antimicrobial susceptibility pattern varied with resistance with amoxicillin and co-trimoxazole being the highest (93\%) followed by, gentamycin (87\%), cefuroxime (84\%), Nalidixic acid (79\%), Amoxicillin clavulanic acid (62.5\%), Ciprofloxacin (62\%), ceftriaxone (55\%),Ceftazidime (54\%), chloramphenicol (28\%), Nitrofurantoin (25.5\%) and Imipenem (0.5\%) Fig. 2.

Out of the 200 E. coli isolates, 156 (78\%) were MDR (multi-drug resistant) i.e. resistance to more than two different antibiotic classes. Biofilm forming E. coli isolates were more resistant than the non-biofilm formers with $64 \%$ being MDR as compared to $36 \%$ among the non-biofilm forming E. coli as shown in Table 2 below. The likelihood of biofilm positive UPEC isolates to be MDR was statistically significant with a $p$-value of $<0.05$ (within a confidence interval of 95\%).

We carried out PCR detection of virulence genes and in this study the prevalence of fimH, Pap, Sfa, Afa, Hly and Cnf genes in Uropathogenic E. coli was; 53.5, 21, 13, $8 \%, 0$ and $5.5 \%$ respectively (Fig. 3 ).

Biofilm formers had more adhesin genes (Fim, Pap, $S f a$ and $A f a$ ) than the non-biofilm formers with Fim being the most predominant virulence gene as shown in Fig. 4.

Biofilm production was not significantly associated with the expression of any of the virulence genes.

\section{Discussion}

Biofilm forming bacteria are a common cause of recurrent, and complicated UTIs which are normally associated with MDR bacteria [1]. Understanding the pathogenesis and factors associated with biofilm formation is key to the development of new therapies [19]. In this study we sought to determine the biofilm forming capability, presence of virulence genes and antimicrobial susceptibility pattern of UPEC clinical isolates in Uganda.

Among 200 E. coli isolates subjected to biofilm production, the majority of the isolates, 125 (62.5\%) were biofilm formers on Congo Red Agar (CRA). This was similar to many previous studies [20-22]. In this study we carried out antibiotic susceptibility pattern on all UPEC isolates in their planktonic state. The biofilmforming isolates showed maximum resistance to Ampicillin and Cotrimoxazole (93\%) followed by Gentamycin (87\%), Cefuroxime (84\%) and Nalidixic Acid (79\%). Though resistance to different antibiotics was generally high, biofilm forming organisms were more MDR (64\%) compared to non-biofilm formers and this was statistically significant with a $p$-value of $<0.05$. Our findings are in agreement with the suggest that suggest biofilms to be associated with increased resistance to antibiotics [23-25].

Previous studies have also indicated that biofilmforming bacteria tend to exhibit higher resistance than planktonic cells due to the tough polymeric matrix that impends antibiotic penetration [26].

In this study, biofilm-forming organisms showed marked resistance to most commonly used antibiotics such as Ciprofloxacin, Ceftriaxone, and Gentamycin. This was also similar in a study by Neupane et al [12]. These findings underscore the need to regulate the use of antimicrobials and institutionalization of antimicrobial stewardship programs in hospitals to limit the

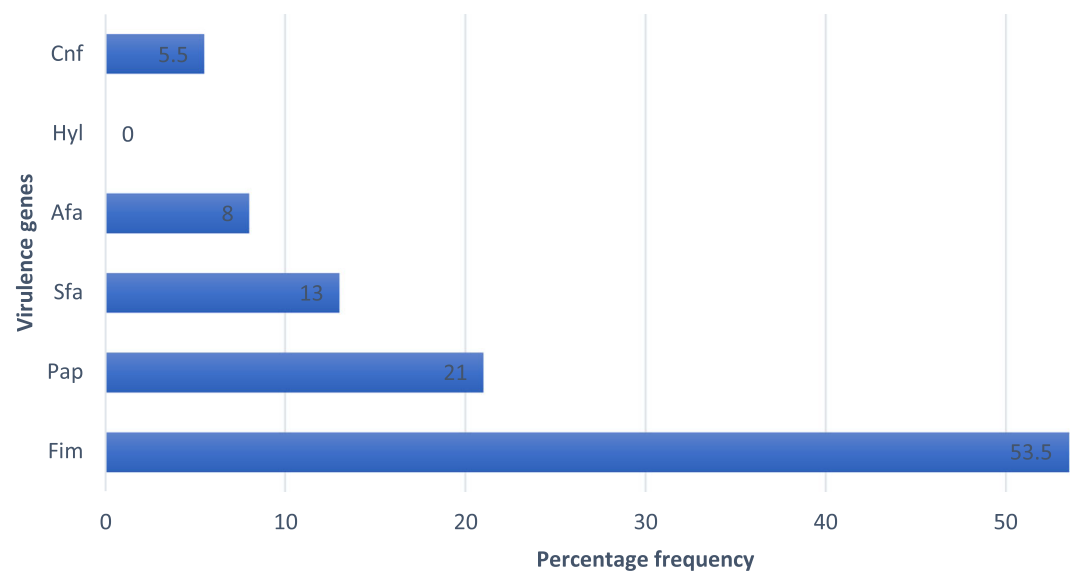

Fig. 3 Percentage frequency of Uropathogenic E.coli virulence genes 


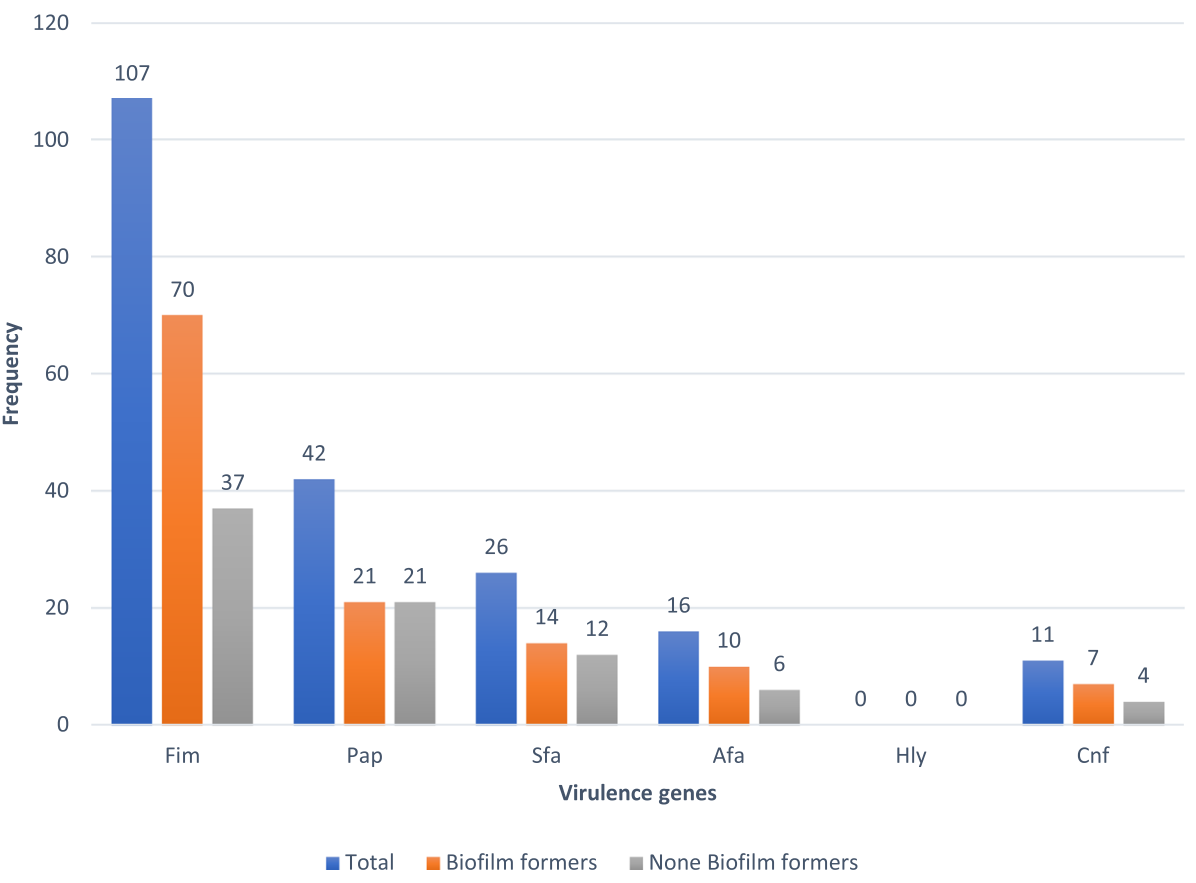

Fig. 4 Frequency of virulence genes among Biofilm and None Biofilm forming Uropathogenic E.coli isolates

spread of resistant microorganisms [27]. In Uganda there is no regulation of use of antibiotics with patients having access to over the counter prescriptions, this has been one of the major drivers of antibiotic resistance in the communities [28].

In the present study the prevalence of Fim, Pap, Sfa, Afa, Hly and Cnf genes in UPEC were determined and the results showed that among biofilm producers, Fim was the most prevalent Urovirulence gene followed by Pap, Sfa, Afa and Cnf. This was similar to other studies $[29,30]$. In our study biofilm production was not associated with any of the virulence genes or resistance to any particular antibiotic. This was however different from other studies. A study by Manuela et al. reported that biofilm production was significantly associated with fluoroquinolone resistance [30]. In another similar study by Zamani et al it was found out that biofilm-producing UPEC were significantly associated with Fim gene [31].

\section{Conclusions}

This study demonstrated a high tendency among the UPEC isolates to form a biofilm. The biofilm-forming organisms were more MDR, produced more virulence genes compared to the non-biofilm forming organisms. Therefore, knowledge of biofilm formation, virulence factors and their antibiotic susceptibility pattern is key to guide the management of patients with biofilm associated infections.

\section{Supplementary information}

Supplementary information accompanies this paper at https://doi.org/10. 1186/s12879-020-05186-1.

\section{Additional file 1.}

\section{Abbreviations}

CLSI: Clinical and laboratory standards institute; DNA: Deoxyribose nucleic acid; MDR: Multi drug resistance; PCR: Polymerase chain reaction; SOPs: Standard Operating procedures; UPEC: Uropathogenic E. coli

\section{Acknowledgements}

Not applicable.

\section{Authors' contributions}

PK performed all the experiments, designed and implemented the study; FN, participated in designing the study and laboratory experiments, CFN, BB, and IA guided in the study design and implementation. The authors helped writing, read and approved the final manuscript.

\section{Funding}

This work was supported in part by the DELTAS Africa Initiative [grant \# 107743/Z/15/Z]. The DELTAS Africa Initiative is an independent funding scheme of the African Academy of Sciences (AAS), Alliance for Accelerating Excellence in Science in Africa (AESA), and supported by the New Partnership for Africa's Development Planning and Coordinating Agency (NEPAD Agency) with funding from the Wellcome Trust (Grant no. 107743) and the UK Government. The funders had no role in study design, data collection and analysis, decision to publish, or preparation of the manuscript.

Availability of data and materials

All data generated or analyzed during this study are included in this published article [and its supplementary information files]. DOl; https://doi. org/10.6084/m9.figshare.11321936 Fig share.

Ethics approval and consent to participate

The study obtained approval from the Research and Ethics committee of the School of Biomedical Sciences, College of Health Sciences Makerere 
University (SBS-HDREC-515). The Ethics Committee waived the requirement for informed consent as the investigated isolates were obtained from clinical specimens referred to the diagnostic laboratory as part of routine care

\section{Consent for publication}

Not applicable.

\section{Competing interests}

The authors declare that they have no competing interests.

\section{Author details}

'Department of Medical Microbiology, College of Health Sciences Makerere University, Kampala, Uganda. ${ }^{2}$ Department of Medical Biochemistry, College of Health Sciences Makerere University, Kampala, Uganda. ${ }^{3}$ Department of Medicine, College of Health Sciences Makerere University, Kampala, Uganda.

Received: 9 December 2019 Accepted: 22 June 2020

Published online: 29 June 2020

\section{References}

1. Flores-Mireles AL, Walker JN, Caparon M, Hultgren SJ. Urinary tract infections: epidemiology, mechanisms of infection and treatment options. Nat Rev Microbiol. 2015:13(5):269.

2. Ejrnæs K. Bacterial characteristics of importance for recurrent urinary tract infections caused by Escherichia coli. Dan Med Bull. 2011;58(4):B4187.

3. Terlizzi ME, Gribaudo G, Maffei ME. UroPathogenic Escherichia coli (UPEC) infections: virulence factors, bladder responses, antibiotic, and non-antibiotic antimicrobial strategies. Front Microbiol. 2017;8:1566.

4. Spencer JD, Schwaderer AL, Becknell B, Watson J, Hains DS. The innate immune response during urinary tract infection and pyelonephritis. Pediatr Nephrol [Internet]. 2013;29(7):1139-49Available from:. https://doi.org/10. 1007/s00467-013-2513-9.

5. Donlan RM. Biofilms: microbial life on surfaces. Emerg Infect Dis. 2002;8(9):881.

6. Nandakumar V, Chittaranjan S, Kurian VM, Doble M. Characteristics of bacterial biofilm associated with implant material in clinical practice. Polym J. 2013:45(2):137

7. Davies J, Davies D. Origins and evolution of antibiotic resistance. Microbiol Mol Biol Rev. 2010;74(3):417-33.

8. Sarowska J, Futoma-Koloch B, Jama-Kmiecik A, Frej-Madrzak M, Ksiazczyk M, Bugla-Ploskonska G, et al. Virulence factors, prevalence and potential transmission of extraintestinal pathogenic Escherichia coli isolated from different sources: recent reports. Gut Pathog. 2019;11(1):10.

9. Lüthje $\mathrm{P}$, Brauner A. Virulence factors of uropathogenic $E$. coli and their interaction with the host. In: Advances in microbial physiology: Elsevier; 2014. p. 337-72. https://doi.org/10.1016/bs.ampbs.2014.08.006, https:// pubmed.ncbi.nlm.nih.gov/25476769/.

10. Limoli DH, Jones CJ, Wozniak DJ. Bacterial extracellular polysaccharides in biofilm formation and function. Microbiol Spectr. 2015;3(3). Available from: https://doi.org/10.1128/microbiolspec.MB-0011-2014.

11. Ali I, Rafaque Z, Ahmed S, Malik S, Dasti Jl. Prevalence of multi-drug resistant uropathogenic Escherichia coli in Potohar region of Pakistan. Asian Pac J Trop Biomed. 2016;6(1):60-6.

12. Neupane S, Pant ND, Khatiwada S, Chaudhary R, Banjara MR. Correlation between biofilm formation and resistance toward different commonly used antibiotics along with extended spectrum beta lactamase production in uropathogenic Escherichia coli isolated from the patients suspected of urinary tract infections visit. Antimicrob Resist Infect Control. 2016;5(1):5.

13. Parveen S, Lukasik J, Scott TM, Tamplin ML, Portier KM, Sheperd S, et al. Geographical variation in antibiotic resistance profiles of Escherichia coli isolated from swine, poultry, beef and dairy cattle farm water retention ponds in Florida 1. J Appl Microbiol. 2006;100(1):50-7.

14. Donelli G, Vuotto C. Biofilm-based infections in long-term care facilities. Future Microbiol. 2014;9(2):175-88.

15. Karam MRA, Habibi M, Bouzari S. Relationships between virulence factors and antimicrobial resistance among Escherichia coli isolated from urinary tract infections and commensal isolates in Tehran, Iran. Osong public Heal Res Perspect. 2018;9(5):217.

16. Ahmed $\mathrm{OB}$, Asghar $\mathrm{AH}$, Elhassan MM. Comparison of three DNA extraction methods for polymerase chain reaction (PCR) analysis of bacterial genomic DNA. African J Microbiol Res. 2014;8(6):598-602.
17. Zhao R, Shi J, Shen Y, Li Y, Han Q, Zhang X, et al. Phylogenetic distribution of virulence genes among ESBL-producing uropathogenic Escherichia coli isolated from long-term hospitalized patients. J Clin diagnostic Res JCDR. 2015:9(7):DC01.

18. Jain A, Agarwal A. Biofilm production, a marker of pathogenic potential of colonizing and commensal staphylococci. J Microbiol Methods. 2009;76(1): 88-92.

19. Römling $U$, Balsalobre $C$. Biofilm infections, their resilience to therapy and innovative treatment strategies. J Intern Med. 2012;272(6):541-61.

20. Subramanian P, Shanmugam N, Sivaraman U, Kumar S, Selvaraj S. Antiobiotic resistance pattern of biofilm-forming uropathogens isolated from catheterised patients in Pondicherry, India. Australas Med J. 2012;5(7):344.

21. Dash D, Sarangi G, Patro P, Chayani N. Study of biofilm production in Escherichia coli causing urinary tract infection and its correlation with antimicrobial resistance. J Acad Clin Microbiol. 2018;20(2):88.

22. Sudheendra KR, Basavaraj PV. Analysis of antibiotic sensitivity profile of biofilm-forming uropathogenic Escherichia coli. J Nat Sci Biol Med. 2018; 9(2):175.

23. Reisner A, Krogfelt KA, Klein BM, Zechner EL, Molin S. In vitro biofilm formation of commensal and pathogenic Escherichia coli strains: impact of environmental and genetic factors. J Bacteriol. 2006;188(10):3572-81.

24. Ong C-LY, Ulett GC, Mabbett AN, Beatson SA, Webb RI, Monaghan W, et al. Identification of type 3 fimbriae in uropathogenic Escherichia coli reveals a role in biofilm formation. J Bacteriol. 2008:190(3):1054-63.

25. Ponnusamy $P$, Natarajan $V$, Sevanan M. In vitro biofilm formation by uropathogenic Escherichia coli and their antimicrobial susceptibility pattern. Asian Pac J Trop Med. 2012;5(3):210-3.

26. Singh S, Singh SK, Chowdhury I, Singh R. Understanding the mechanism of bacterial biofilms resistance to antimicrobial agents. Open Microbiol J. 2017; 11:53.

27. Baur D, Gladstone BP, Burkert F, Carrara E, Foschi F, Döbele S, et al. Effect of antibiotic stewardship on the incidence of infection and colonisation with antibiotic-resistant bacteria and Clostridium difficile infection: a systematic review and meta-analysis. Lancet Infect Dis. 2017;17(9):990-1001.

28. Namuwenge JM, Mwesige OG, Mukanga N. Over-the-counter suboptimal dispensing of antibiotics in Uganda. J Multidiscip Healthc. 2013;303Available from: https://doi.org/10.2147/JMDH.S49075.

29. Ahmed N, Zeshan B, Naveed M, Afzal M, Mohamed M. Antibiotic resistance profile in relation to virulence genes fimH, hlyA and usp of uropathogenic E. coli isolates in Lahore, Pakistan. Trop Biomed. 2019;36(2):559-68.

30. Stephenson SAM, Brown PD. Distribution of virulence determinants among antimicrobial-resistant and antimicrobial-susceptible Escherichia coli implicated in urinary tract infections. Indian J Med Microbiol. 2016;34(4):448.

31. Zamani $H$, Salehzadeh A. Biofilm formation in uropathogenic Escherichia coli: association with adhesion factor genes. Turkish J Med Sci. 2018;48(1): $162-7$.

\section{Publisher's Note}

Springer Nature remains neutral with regard to jurisdictional claims in published maps and institutional affiliations.

Ready to submit your research? Choose BMC and benefit from:

- fast, convenient online submission

- thorough peer review by experienced researchers in your field

- rapid publication on acceptance

- support for research data, including large and complex data types

- gold Open Access which fosters wider collaboration and increased citations

- maximum visibility for your research: over $100 \mathrm{M}$ website views per year

At BMC, research is always in progress.

Learn more biomedcentral.com/submissions 